\title{
Evaluation of through-time radial GRAPPA for functional cardiac imaging in a patient population
}

\author{
Nicole Seiberlich ${ }^{1 *}$, Gunhild Aandal ${ }^{2}$, Victoria Yeh ${ }^{3}$, Trevor Jenkins ${ }^{4}$, Mark A Griswold ${ }^{5,1}$, Robert Gilkeson ${ }^{5}$, \\ Vikas Gulani ${ }^{5,1}$, Prabhakar Rajiah ${ }^{5}$
}

From 17th Annual SCMR Scientific Sessions

New Orleans, LA, USA. 16-19 January 2014

\section{Background}

Real-time cardiac imaging with through-time radial GRAPPA has been shown to yield high quality functional images [Seiberlich, et al. MRM2011 Feb;65(2):492-505]. The goal of this work is to evaluate through-time radial GRAPPA in terms of overall scan time, quantitative measures of ESV, EDV, and EF, and image quality in a patient population.

\section{Methods}

63 patients scheduled for routine CMR examinations were scanned on a $1.5 \mathrm{~T}$ Siemens Avanto scanner with 12-18 receiver coils in this IRB and HIPPA-compliant study. The gold-standard gated and breathheld shortaxis cardiac functional examination was performed for each patient with a temporal resolution between 31 and $62 \mathrm{~ms}$, GRAPPA $\mathrm{R}=2$, and an in-plane resolution between 1.4-2.6 $\mathrm{mm}^{2}$. Real-time, ungated and freebreathing scans with through-time radial GRAPPA were also performed with a radial bSSFP sequence, temporal resolution of $42.2 \mathrm{~ms}$, in-plane resolution of $2.3 \mathrm{~mm}^{2}$, and a reduction factor of 8 (16 projections for a $128^{2}$ matrix). Either 26 (23 patients) or 6 (40 patients) calibration frames were collected for the through-time radial GRAPPA scan. The total scan times were noted for each patient and type of scan. ESV, EDV, and EF values were computed for both the standard and the real-time cardiac datasets and evaluated for agreement using two-sample t-tests. Images were rated for specific features on a scale of 1 (no visibility) to 4 (excellent) by two board-certified cardiac imagers. The distributions of

${ }^{1}$ Biomedical Engineering, Case Western Reserve University, Cleveland, Ohio, USA

Full list of author information is available at the end of the article review ratings were compared using the Wilcoxon test. A two-sample t-test was performed to compare the scan durations.

\section{Results}

Examples images are shown in Figure 1. The results of the statistical analyses are shown in Table 1. The measures of ESV, EDV, and EF based on the breathhold gold-standard images and the real-time radial GRAPPA images are statistically equivalent. Similarly, statistical analysis showed that the image quality scores for the endocardial border definition, myocardium, cardiac motion were equivalent for the two methods. The raters weakly preferred the standard images for visualizing papillary muscle when only 6 calibration frames were used, and strongly preferred the standard images for blood pool and mitral valve visualization in all cases. Scan time was significantly shorter when using throughtime radial GRAPPA with either 6 or 26 calibration frames, where the averages were $5.7 \mathrm{~min}$ with gold-standard imaging vs. $4.7 \mathrm{~min}$ with radial GRAPPA using 26 calibration frames and 2.8 min with 6 calibration frames.

\section{Conclusions}

Real-time, free-breathing functional cardiac imaging using through-time radial GRAPPA offers EF values equivalent to gold-standard cine imaging with shorter overall scan times in a general patient population. While the use of more calibration frames for through-time radial GRAPPA slightly improves the image quality, as few as 6 calibration frames per slice can be used to reduce functional imaging time to less than $3 \mathrm{~min}$. 


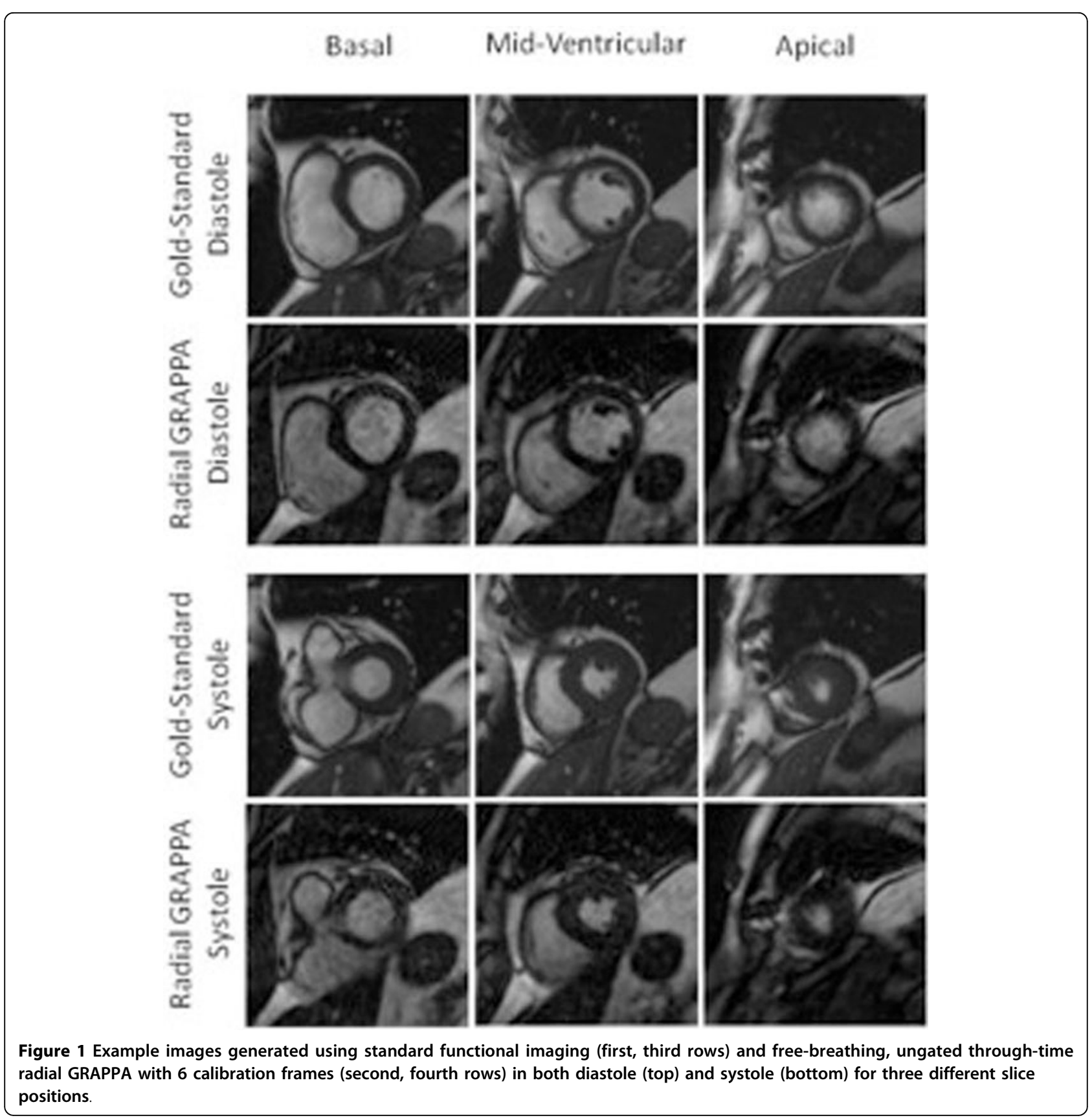

Table 1 Results of statistical analyses for different image features

\begin{tabular}{|c|c|c|c|c|}
\hline & & $\begin{array}{l}\text { Gold-Standard vs. Radial } \\
\text { GRAPPA }\end{array}$ & $\begin{array}{c}\text { Gold-Standard vs. Radial GRAPPA with } \\
6 \text { Cal Frames }\end{array}$ & $\begin{array}{c}\text { Gold-Standard vs. Radial GRAPPA with } \\
26 \text { Cal Frames }\end{array}$ \\
\hline \multirow{3}{*}{$\begin{array}{l}\text { Quantitative } \\
\text { Parameters }\end{array}$} & EF & 0.77 & 0.90 & 0.73 \\
\hline & ESV & 0.97 & 0.93 & 0.87 \\
\hline & EDV & 0.82 & 0.78 & 0.99 \\
\hline \multirow{2}{*}{$\begin{array}{l}\text { Qualitative } \\
\text { Parameters }\end{array}$} & Endocardial & 0.23 & 0.05 & 0.73 \\
\hline & Papillary & $0.03 *$ & $0.02 *$ & 0.71 \\
\hline
\end{tabular}


Table 1 Results of statistical analyses for different image features (Continued)

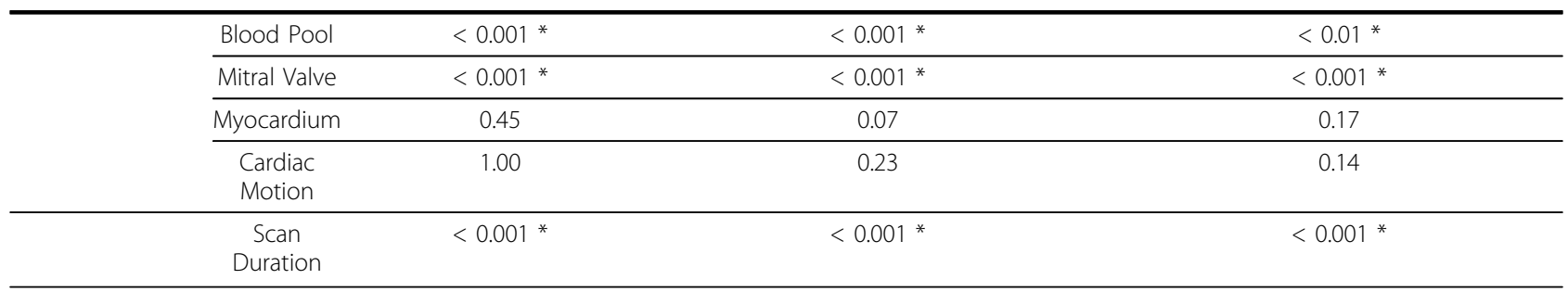

* denotes statistically significant differences

\section{Funding}

NIH (R00EB011527, RO1HL094557, and UL1 RR024989) and Siemens Medical Solutions.

\section{Authors' details}

${ }^{1}$ Biomedical Engineering, Case Western Reserve University, Cleveland, Ohio, USA. ${ }^{2}$ Haraldsplass Deaconess Hospital, Bergen, Norway. ${ }^{3}$ Case Western Reserve University School of Medicine, Cleveland, Ohio, USA. ${ }^{4}$ Cardiovascular Medicine, Harrington Heart \& Vascular Institute, University Hospitals of Cleveland, Cleveland, Ohio, USA. ${ }^{5}$ Radiology, University Hospitals of Cleveland, Cleveland, Ohio, USA.

Published: 16 January 2014

- Convenient online submission

- Thorough peer review

- No space constraints or color figure charges

- Immediate publication on acceptance

- Inclusion in PubMed, CAS, Scopus and Google Scholar

- Research which is freely available for redistribution 